Med Clin North Am. 2013 January ; 97(1): 59-74. doi:10.1016/j.mcna.2012.10.010.

\title{
Obesity and Diabetic Kidney Disease
}

\author{
Christine Maric-Bilkan, PhD \\ Department of Physiology and Biophysics, University of Mississippi Medical Center, Jackson, MS, \\ USA
}

\section{Keywords}

kidney; obesity; diabetes; proteinuria; hyperfiltration; hypertension; glomerulopathy; diabetic nephropathy

\section{Introduction}

The prevalence of obesity (body mass index, BMI $\geq 30 \mathrm{~kg} / \mathrm{m}^{2}$ ) has risen to epidemic proportions and continues to be a major health problem worldwide ${ }^{1-3}$. The high prevalence of obesity is closely linked to the increased incidence of a number of chronic diseases, including type 2 diabetes, hypertension and cardiovascular disease ${ }^{2,4-8}$. Obesity, as well as type 2 diabetes, hypertension and cardiovascular disease are all risk factors for chronic kidney disease (CKD) and end-stage renal disease (ESRD) ${ }^{9-13}$, inasmuch as the presence of one or more of these risk factors multiplies the overall risk for disease development and progression (Figure 1). In addition, evidence suggests that obesity may also increase the risk of and ESRD independent of type 2 diabetes and hypertension ${ }^{14-1616}$. However, the precise mechanisms by which obesity independently, or in concert with type 2 diabetes and hypertension contributes to the development and/or progression of CKD and ESRD are not completely understood.

The two leading causes of ESRD are type 2 diabetes and hypertension, which together account for over $70 \%$ of patients with ESRD ${ }^{17-18}$. Since the growing prevalence of obesity is a major driving force for the continued increase in the prevalence of type 2 diabetes 7,19 , it is often difficult to dissect out the individual contribution of either obesity, type 2 diabetes or hypertension to the development of ESRD. In fact, the pathophysiology of type 2 diabetes-related renal disease (i.e. diabetic nephropathy) and obesity-related renal disease are almost identical. Indeed, they both evolve in a sequence of stages beginning with initial increases in glomerular filtration rate (GFR) and intraglomerular capillary pressure $\left(\mathrm{P}_{\mathrm{Gc}}\right)$, glomerular hypertrophy and microalbuminuria ${ }^{20-21}$. Elevated systolic blood pressure further exacerbates the disease progression to proteinuria, nodular glomerulosclerosis and tubulointerstitial injury and a decline in GFR leading to ESRD ${ }^{22-23}$. Diabetes- and obesityrelated renal disease also have common initiating events which include interactions among multiple metabolic and hemodynamic factors which activate common intracellular signaling pathways that in turn trigger the production of cytokines and growth factors, leading to renal

(C) 2012 Elsevier Inc. All rights reserved.

Corresponding author: Christine Maric-Bilkan, Department of Physiology \& Biophysics, University of Mississippi Medical Center, 2500 North State Street, Jackson, MS, 39216-4505, USA, Phone: 601-984-1818; Fax: 601-984-1817; cmaric@ umc.edu.

Publisher's Disclaimer: This is a PDF file of an unedited manuscript that has been accepted for publication. As a service to our customers we are providing this early version of the manuscript. The manuscript will undergo copyediting, typesetting, and review of the resulting proof before it is published in its final citable form. Please note that during the production process errors may be discovered which could affect the content, and all legal disclaimers that apply to the journal pertain. 
disease. The purpose of this review is to provide perspectives regarding the mechanisms by which obesity may lead to ESRD and to discuss prevention strategies and treatment for obesity-related renal disease.

\section{Epidemiology of obesity and diabetes-related kidney disease}

\section{Prevalence of Obesity and type 2 diabetes}

Based on the most recent report from the National Health and Nutrition Examination Survey (NHANES) examining obesity prevalence among U.S. adults, adolescents, and children, more than one-third of adults and almost $17 \%$ of children and adolescents were obese in 2009-2010 24-25. Interestingly, while there has been a significant increase in obesity prevalence among men and boys over the last decade, no changes were seen among women and girls. With the prevalence of obesity being 35.5\% among adult men, 35.8\% among adult women and $16.9 \%$ amongst children and adolescents of both sexes, the Healthy People 2010 goals of $15 \%$ obesity among adults and $5 \%$ obesity among children are far from being met.

Similar to obesity, the global prevalence of type 2 diabetes has more than doubled in the last 30 years and is predicted to continue to rise at an alarming rate. According to the World Health Organization, in 2008, almost 350 million people worldwide have diabetes, $90 \%$ of which are type 2 diabetic ${ }^{26}$. While the major driving force for the increase in the prevalence of type 2 diabetes is obesity, other factors, including genetic and environmental are also important contributors to the development of type 2 diabetes. Accumulating evidence suggests that this markedly high prevalence of both obesity and type 2 diabetes contribute to the increased incidence of chronic diseases, including CKD and ESRD ${ }^{9-13}$.

\section{Obesity, diabetes and chronic kidney disease}

Obesity is a well recognized risk factor for both type 2 diabetes and hypertension, which are leading causes of both CKD and ESRD ${ }^{27}$. Analysis of data from the Framingham Heart study which included over 2,600 patients with no CKD at baseline showed an increased risk of developing stage 3 CKD in obese (BMI $\geq 30 \mathrm{~kg} / \mathrm{m}^{2}$ ), but not overweight (BMI $25-30 \mathrm{~kg} /$ $\mathrm{m}^{2}$ ) patients after 18.5 years of follow-up ${ }^{9}$. However, this relationship was no longer significant after adjustment for known cardiovascular disease risk factors, including diabetes and hypertension. Numerous other studies have also demonstrated that the association between obesity and CKD is mediated though risk factors including diabetes, hypertension and other elements of the metabolic syndrome ${ }^{10,16,28-30}$.

While studies clearly indicate that the high risk of obesity-related CKD is driven by diabetes and hypertension, there are a number of other studies that suggest that obesity can lead to the development of CKD independently of either diabetes or hypertension. Specifically, the data from the Hypertension Detection and Follow-Up Program show that the incidence of CKD after a 5 year follow-up, in a cohort of 5897 patients with hypertension and no CKD at baseline, was $28 \%$ in patients with normal BMI, $31 \%$ in overweight patients and $34 \%$ in obese patients ${ }^{16}$. This risk for CKD persisted in the overweight and obese patients even after adjustment for covariates, including type 2 diabetes, suggesting that obesity increases the risk of CKD independent of type 2 diabetes. Further supporting the notion that obesity increases the risk of CKD independent of diabetes and hypertension is the Physician's Health Study, a large cohort of initially healthy men, in which BMI was associated with increased risk for CKD over 14 years ${ }^{31}$. Furthermore, in 74,986 prehypertensive individuals participating in the first Health Study in Nord-Trøndelag study in Norway, the risk of CKD over 21 years was shown to increase dramatically with obesity ${ }^{32}$. In addition to increasing the risk of CKD, obesity has also been suggested to have a higher rate of decline of GFR and progress faster to ESRD ${ }^{33}$. 


\section{Obesity, diabetes and ESRD}

Several studies have shown that increased BMI is an independent risk factor for ESRD. In a cohort of 320,252 adult patients of Kaiser Permanente that were followed for 15-35 years, BMI was found to be a strong and common risk factor for ESRD ${ }^{10}$. This relationship between BMI and ESRD persisted even after controlling for baseline blood pressure and diabetes. Similarly, in a population-based, case-control study in Sweden, obesity was shown to be an important and potentially preventable-risk factor for ESRD ${ }^{11}$. This study also showed that the coexistence of obesity and diabetes doubled the risk of new onset kidney disease. One study compared the temporal trends in mean BMI and obesity prevalence among incident ESRD by year of dialysis initiated between 1995 and 2002, and these trends were compared with those in the US population during this same period ${ }^{34}$. This study found that among incident patients with ESRD, mean BMI at the start of dialysis increased from 25.7 to $27.5 \mathrm{~kg} / \mathrm{m}^{2}$, and total obesity and stage 2 obesity increased by 33 and $63 \%$, respectively. The slope of mean BMI at initiation of dialysis over the 8 years of follow-up was $\sim 2$-fold higher in the incident ESRD population compared with the US population for all age groups ${ }^{34}$.

In contrast to the vast majority of studies suggesting that obesity is a risk factor for CKD and ESRD, some studies have reported that high BMI is associated with greater survival in patients on maintenance hemodialysis ${ }^{35-36}$. This phenomenon, commonly referred to as the "obesity paradox" reasons that in patients receiving long-term hemodialysis, larger body size (i.e. larger BMI) with more muscle mass (i.e. higher serum creatinine concentration) is associated with greater survival. These observations indicate that it's the increase in muscle mass, rather than increase in total body weight that confers protection, suggesting that BMI may not always be the most reliable index of CKD risk, at least in certain patient populations. Indeed, other studies indicate that visceral or central obesity, but not BMI is associated with incident $\mathrm{CKD}^{37}$ and increased cardiovascular disease in CKD patients ${ }^{38}$. Thus, it is conceivable that overall weight loss with a concomitant increase in muscle mass may be an effective treatment strategy in preventing obesity-associated CKD and ESRD.

\section{Pathophysiology of obesity and diabetes-related kidney disease}

Obesity-related, similar to diabetes-related renal disease, is associated with physiological, anatomical and pathological changes in the kidney (Figure 2). Both obesity and diabetes renal disease evolve in a sequence of stages beginning with initial increases in GFR and $\mathrm{P}_{\mathrm{Gc}}$, glomerular hypertrophy and microalbuminuria ${ }^{20-21}$. Elevated systolic blood pressure further exacerbates the disease progression to proteinuria, nodular glomerulosclerosis and tubulointerstitial injury and a decline in GFR leading to ESRD ${ }^{22-23}$. Furthermore, both obesity- and diabetes-related renal disease also share common initiating events which include interactions among multiple metabolic and hemodynamic factors which activate common intracellular signaling pathways that in turn trigger the production of cytokines and growth factors, leading to renal disease (Figure 3).

\section{Obesity, diabetes and glomerular hemodynamics}

Experimental studies in diet-induced obese dogs and genetically-induced obese rats show that one of the earliest changes in renal hemodynamics in response to the obese state is glomerular hyperfiltration. Specifically, dogs fed a high fat diet for only 5-6 weeks and obese Zucker rats show an increase in GFR ${ }^{39-40}$. These changes in GFR are reversible, at least in the obese Zucker rats, in which food restriction and was associated with attenuation of glomerular hyperfiltration, possibly due to decreased protein intake or overall weight loss ${ }^{40}$. These observations in experimental models have also been confirmed in obese humans. Studies have shown that obese individuals exhibit around 50\% higher GFR 
compared with lean individuals ${ }^{41}$. While there is still some debate as to the mechanisms underlying obesity-related glomerular hyperfiltration, the most likely explanation is increased sodium reabsorption by the proximal tubule or loop of Henle, leading to tubuloglomerular feedback (TGF)-mediated reduction in afferent arteriolar resistance, increased $\mathrm{P}_{\mathrm{Gc}}$ and thus increased GFR ${ }^{42}$. This TGF-driven dilation of afferent arterioles and resultant impairment of renal autoregulation, in turn, allows increases in blood pressure to be transmitted to the glomerulus causing further increases in $\mathrm{P}_{\mathrm{Gc}}$ and subsequent glomerular injury 43 . This may especially be important in individuals with reduced nephron number in which there is a greater risk of enhanced glomerular blood pressure transmission due to the substantially greater preglomerular vasodilation ${ }^{43}$. There is also evidence for the increased activation of the renin-angiotensin-aldosterone system (RAAS) and increased renal sympathetic tone as important stimuli for increased sodium reabsorption exacerbating the renal hemodynamic changes associated with obesity $44-46$.

It is generally thought that the initial increase in GFR associated with obesity likely serves as an early compensatory response that allows for restoration of salt balance despite continued increases in tubular reabsorption. However, over long-term, glomerular hyperfiltration may contribute to the development of renal injury, especially if combined with hypertension. Supporting this notion are studies showing that weight loss reduces glomerular hyperfiltration and subsequent renal injury 41,47 .

Similar to obesity-associated glomerular hyperfiltration, renal vasodilation and increases in GFR and $\mathrm{P}_{\mathrm{Gc}}$ also characterize early stages of diabetes-associated renal disease ${ }^{48}$. Although the precise mechanisms underlying diabetes-associated glomerular hyperfiltration remain inconclusive, it is thought that mechanisms similar to those occurring in obesity drive the initial increase in GFR. Specifically, reduced delivery of salt to the macula densa, as a consequence of increased proximal reabsorption of glucose and sodium, reduces afferent arteriolar resistance leading to increased $\mathrm{P}_{\mathrm{Gc}}$ and GFR via attenuated TGF ${ }^{49-51}$. In addition, afferent vasodilation and efferent vasoconstriction in response to circulating or locally formed vasoactive factors (e.g. angiotensin II (Ang II) and endothelin) produced in response to hyperglycemia or shear stress are also believed to contribute to the development of diabetes-associated glomerular hyperfiltration ${ }^{52-53}$.

Interestingly, while the majority of studies suggest that the mechanisms underlying glomerular hyperfiltration due to obesity and diabetes are similar, there is some evidence to suggest that hyperglycemia and obesity may have at least partially additive effects on glomerular hemodynamics. Since both obesity and diabetes co-exist with elements of the metabolic syndrome, including hypertension, it is often difficult to separate the effects of each element on glomerular hemodynamics and progression of renal injury, at least in humans. Experimental studies however provide some mechanistic insights. Specifically, mice lacking the gene for the melanocortin-4 receptor are obese, hyperinsulinemic and hyperleptinemic but normotensive at 55 weeks of age and exhibit moderately increased GFR compared with their wild-type counterparts ${ }^{54}$. However, when rendered hypertensive via treatment with $\mathrm{N}(\mathrm{G})$-nitro-L-arginine methyl ester (L-NAME), they develop prominent glomerular hyperfiltration, suggesting that increases in blood pressure may exacerbate obesity-related increases in GFR. These data support the concept of a synergistic effect of various components of obesity, metabolic syndrome, diabetes and hypertension on glomerular hemodynamics.

While early stages of both obesity- and diabetes-related renal disease are characterized by glomerular hyperfiltration, one of the hallmarks of advanced stages of the disease is the decline in GFR. Unlike studies examining the mechanisms underlying glomerular hyperfiltration, much less is known about the mechanisms underlying the decline in GFR 
characteristic of advanced diabetic and obesity-related nephropathy. The main reason for this lack of knowledge is the lack of appropriate experimental models that mimic the advanced stages of the disease: the majority of experimental models of obesity- or diabetesrelated renal injury never really develop overt nephropathy and are in a permanent state of glomerular hyperfiltration. However, the existing evidence suggests that obesity and diabetes are states of low-grade inflammation and oxidative stress, both of which may lead to kidney damage, progressive loss of nephrons and decline in GFR over time. In addition, hyperlipidemia has been linked to reduced GFR associated with advanced diabetic nephropathy. Several clinical studies have demonstrated the importance of lipid control in preserving GFR in patients with diabetes ${ }^{55}$. However, additional studies are warranted to examine whether beneficial effects of lipid lowering in diabetes- and obesity-related nephropathy are due to improvement in the lipid profile or more direct renoprotection.

\section{Hypertension as a driving force for obesity- and diabetes-related kidney disease}

The nearly linear relationship between BMI and blood pressure in diverse populations throughout the world ${ }^{35,56-58}$ has led to the notion that obesity contributes to the development of hypertension. Indeed, numerous clinical, population and basic research studies have shown that visceral obesity, the main driver of type 2 diabetes, raises blood pressure ${ }^{59-60}$. Data from the Framingham Heart Study as well as other population-based studies indicate that excess weight gain may account for as much as 78 percent of primary (essential) hypertension in men and 65 percent in women ${ }^{61-62}$. In addition, obese individuals have a 3.5 -fold increase in the risk for developing hypertension 56,63 . Furthermore, clinical studies also indicate that weight loss reduces blood pressure in most hypertensive subjects and is effective in primary prevention of hypertension ${ }^{60}$. Discussing the mechanisms underlying obesity-driven hypertension is beyond the scope of this review, but accumulating evidence suggest that physiological, environmental as well as genetic factors all contribute to obesity-related hypertension ${ }^{64}$. Given that the focus of this review is contribution of obesity to development of renal disease, the question that will be asked is how does obesity-related hypertension lead to the development of renal disease?

Several studies have suggested that visceral (but not subcutaneous) obesity induces hypertension, initially by increasing renal tubular sodium reabsorption and causing a hypertensive shift of renal-pressure natriuresis via activation of multiple pathways including the sympathetic nervous system and the RAAS ${ }^{39}, 64-65$. In addition, physical compression of the kidneys due to visceral obesity has also been suggested to contribute to the increase in blood pressure, at least in some experimental models ${ }^{39}$. This increase in blood pressure, alongside increases in $\mathrm{P}_{\mathrm{G}}$, and GFR (discussed below), and other metabolic abnormalities (e.g. dyslipidemia, hyperglycemia) all likely interact to contribute to the initial renal insult. Interestingly, a similar sequence of events has been proposed to contribute to renal injury in the setting of type 2 diabetes, independent of obesity, suggesting that hypertension plays a major role in obesity as well as diabetes-associated renal disease. Hypertension, in addition to contributing to the initial development of renal injury is also an important factor in the disease progression. Indeed, progressive renal injury only occurs when hypertension is superimposed on obesity or diabetes ${ }^{54}$. The importance of tight blood pressure control for treating diabetic nephropathy is recognized in current guidelines, with a recommended target of blood pressure less than $130 / 80 \mathrm{mmHg}{ }^{66}$. Finally, several studies have shown clear renoprotection with respect to slowing progression of nephropathy in patients with type 2 diabetes via blood pressure lowering ${ }^{67-71}$.

\section{Obesity, diabetes and albuminuria}

The earliest clinical manifestation of obesity- and diabetes-related renal injury is microalbuminuria (30-300 mg/day) which, over time, can progresses to overt proteinuria 
(300-3000 mg/day) ${ }^{72-74}$. Microalbuminuria, in turn, signifies increased risk of progression to ESRD and cardiovascular disease ${ }^{74}$. Studies in both non-diabetic and diabetic overweight individuals have shown that increases in urine albumin excretion strongly correlate with increases in body weight and other markers of obesity, including BMI, waist circumference and waist-to-hip ratio ${ }^{75-78}$. In the Prevention of Renal and Vascular End stage Disease (PREVEND) study the prevalence of microalbuminuria, in both lean and obese individuals, correlated with central obesity even after correction for confounding variables ${ }^{79}$. Further supporting the notion of a direct correlation between BMI and microalbuminuria is the retrospective analysis of the database of a population study showing that the prevalence of microalbuminuria increased from $9.5 \%$ in men with normal BMI to $18.3 \%$ in overweight and $29.3 \%$ in obese men ${ }^{77}$. In a cross-sectional study in a cohort of African-Americans, microalbuminuria was most prevalent in patients with newly diagnosed type 2 diabetes and was independently associated with BMI ${ }^{78}$. Others have shown that even moderate weight reduction in patients with type 2 diabetes with proteinuria, reduces urine protein excretion by approximately $30 \%{ }^{80}$. Furthermore, weight reduction achieved through either dietary caloric restriction or bariatric surgery has been shown to attenuate progression of proteinuria in obese non-diabetic individuals ${ }^{81-82}$.

The development of microalbuminuria, in either non-diabetic or diabetic subjects was traditionally thought to result from damage to the glomerular filtration barrier as a consequence of increases in blood pressure which is transmitted to the glomeruli, raising $\mathrm{P}_{\mathrm{Gc}}$ and GFR. In addition, in the setting of diabetes, hyperglycemia-associated inflammation and oxidative stress have all been shown to contribute to the damage of the glomerular filtration barrier, contributing to the increased leakage of protein across the membrane leading to the development of albuminuria ${ }^{72}$. In the setting of obesity, cytokines including adiponectin have been suggested to play a role in the development of albuminuria. Specifically, the adiponectin knockout mouse exhibits increased baseline albuminuria and podocyte foot process effacement, suggesting that adiponectin regulates podocyte function and thus contribute to the initial development of albuminuria ${ }^{83}$. Apart from the "glomerulocentric" view of the origin of albuminuria, a more recent theory on the mechanisms of albuminuria, especially in the setting of diabetes is that the diabetic milieu also impairs proximal tubular reabsorption of albumin leading to increased urine albumin excretion ${ }^{84}$.

\section{Obesity, diabetes and glomerulopathy}

Accompanying the hemodynamic changes, the early stage of obesity is associated with up to a $40 \%$ increase in kidney weight 39,85 . Histologically, the "obese" kidney is characterized by glomerulomegaly, mesangial expansion and podocytopenia leading to focal segmental glomerulosclerosis $43,86-87$. These features, which precede overt renal insufficiency, have been observed in biopsies from obese humans 88 and experimental models of obesity-related kidney disease, namely the obese Zucker rat ${ }^{89-90}$ and the high-fat fed dogs ${ }^{39}$. However, the degree of glomerulosclerosis appears to be highly variable amongst different experimental models and obese individuals ${ }^{91}$ and some studies indicate that some obese individuals do not even develop glomerulosclerosis, despite the glomerulomegaly ${ }^{87}$. A review of native 6818 renal biopsies indicate that obesity-related glomerulopathy is characterized by lesser segmental sclerosis, less podocyte effacement but more glomerulomegaly compared with idiopathic glomerulosclerosis ${ }^{91}$. However, despite the less pronounced glomerular lesions in obesity-related glomerulopathy, the long-term prognosis of the disease is just as poor. It has been reported that the probabilities of renal survival are 77 and $51 \%$ at 5 and 10 years, respectively 92 and that nephron number may play a significant role in the renal prognosis ${ }^{93}$. Specifically, in patients with unilateral renal agenesis, the decline in renal 
function is most pronounced in obese patients, suggesting that obesity accelerates renal dysfunction in patients with severe reductions in renal mass 93 .

Similar to obesity-related glomerulopathy, early diabetic nephropathy is accompanied by hyperfiltration and microalbuminuria. Histologically, the diabetic kidney exhibits glomerular hypertrophy, widening of the glomerular basement membrane, mesangial expansion, podocytopenia leading to nodular (Kimmelstiel-Wilson) glomerulosclerosis and tubulointerstitial fibrosis 22 . Thus, given the similarities in the histological appearance of the renal lesions from diabetic and obese subjects, it is not surprising that the mechanisms underlying these changes bare many similarities.

\section{Mechanisms of obesity- and diabetes-related glomerulopathy}

Obesity (i.e. visceral adiposity) and diabetes (hyperglycemia) both promote a low grade inflammatory state and are associated with infiltration of macrophages into the kidney. The infiltrated macrophages, in turn, become a source of a whole host of proinflammatory mediators such as tumor necrosis factor-a (TNF-a), interleukin-6 (IL-6), C-reactive protein (CRP), monocyte chemoattractant protein-1 (MCP-1) and macrophage migration inhibitory factor ${ }^{94-95}$. In addition, visceral fat releases adipokines such as adiponectin and leptin into the circulation which also play a role in the pathophysiology of renal injury ${ }^{95}$. Apart from adipokines and inflammatory mediators, vasoactive peptides, such as angiotensin II (Ang II) also contribute to obesity- and diabetes-associated glomerulopathy.

Adiponectin-Obese humans are characterized by consistently low circulating adiponectin levels. However, in patients with CKD and ESRD due to obesity or diabetes, adiponectin levels are increased, possibly due to impaired renal function ${ }^{96-97}$. Experimental studies have shown that genetic deletion of adiponectin is associated with albuminuria and podocyte effacement, which were further exacerbated by diabetes 98 . Treatment of these mice with exogenous adiponectin results in normalization of albuminuria, improvement of podocyte foot process effacement, increased glomerular AMPK activation, and reduced urinary and glomerular markers of oxidative stress ${ }^{83}$. These observations suggest that adiponectin may have a renoprotective effect.

Leptin-While the primary action of leptin is to act on the satiety center to limit food intake, leptin has also been linked to renal disease. Circulating leptin levels are increased in CKD and in patients on hemodialysis ${ }^{99-100}$. Leptin levels are also typically elevated in obese individuals. Mice overexpressing leptin have more renal disease than leptin deficient mice ${ }^{101}$. Long-term infusion of recombinant leptin in rats is associated with proteinuria, increased expression of extracellular matrix proteins (collagen type IV), transforming growth factor-beta (TGF- $\beta$ ) and other pro-inflammatory cytokines, macrophage infiltration and glomerulosclerosis ${ }^{102}$. These observations suggest that, unlike adiponectin, leptin promotes the development of renal injury in both obese and lean subjects.

Inflammatory markers-Both obesity and diabetes are characterized by increased levels of circulating cytokines, including TNF-a and IL-6 ${ }^{103-104}$, and markers of inflammation are inversely associated with measures of kidney function and positively with albuminuria. It is thought that the major source of pro-inflammatory cytokines in obese and diabetic subjects that directly contribute to renal injury are infiltrated macrophages ${ }^{101}$. In addition, renal parenchyma has also been shown to release proinflammatory cytokines in response to hyperglycemia or locally active vasoactive peptides, such as Ang II ${ }^{105}$. Once released, these pro-inflammatory mediators contribute to a low grade chronic inflammatory state that contributes to obesity- and diabetes-associated glomerulopathy. In particular, TNF-a has been shown to reduce the expression of key components of the slit diaphragm, nephrin and 
podocin, thus contributing to podocytopathy ${ }^{106}$. Similarly, IL-6 promotes the expression of adhesion molecules and subsequent oxidative stress ${ }^{107}$, while blocking the IL-6 receptor prevents progression of proteinuria, renal lipid deposition as well as mesangial cell proliferation associated with severe hyperlipoproteinemia ${ }^{108}$. Thus, there is strong evidence for the contribution of inflammation in obesity- and diabetes-associated renal disease.

Other factors-While several vasoactive peptides have been implicated in the pathogenesis of obesity- and diabetes-associated glomerulopathy, the most prominent, and certainly the best described vasoactive hormonal pathways is the RAAS, with Ang II being the most biologically active component. Both obesity and persistent hyperglycemia are associated with an upregulation in the intrarenal RAAS ${ }^{109-110}$. Activation of the RAAS leads to both hemodynamic and cellular effects. Ang II leads to increases in efferent arteriolar vasoconstriction and glomerular pressure, sodium retention and cell proliferation ${ }^{111-113}$. On a cellular level, Ang II activates protein kinase C (PKC) and MAP kinase (MAPK) and transcription factors such as nuclear factor- $\kappa \mathrm{B}$ that lead to the alteration in gene expression of a number of growth factors and cytokines including TGF- $\beta$. TGF- $\beta$, in turn, promotes podocyte apoptosis, mesangial cell proliferation and extracellular matrix synthesis, cellular events that are important in the development of obesity- and diabetesassociated glomerulopathy 114 .

While there are many similarities between the "obese" and "diabetic" kidney, there are some features unique to obesity in the absence of diabetes. Kidneys of obese individuals frequently exhibit glomerular/mesangial lipid deposits (foam cells), supporting the concept of lipotoxicity, i.e. lipid-induced renal injury. This lipid accumulation in the glomerulus then leads to the upregulation of sterol-regulatory element-binding proteins (SREBP-1 and 2), which, in turn, promote podocyte apoptosis and mesangial cell proliferation and cytokine synthesis ${ }^{115}$.

\section{Conclusions}

Obesity and diabetes are major causes of CKD and ESRD, and are thus enormous health concerns worldwide. Both obesity and diabetes, along with other elements of the metabolic syndrome including hypertension are highly interrelated and contribute to the development and progression of renal disease. Studies show that multiple factors act in concert to initially cause renal vasodilation, glomerular hyperfiltration and albuminuria, leading to the development of glomerulopathy. The co-existence of hypertension contributes to the disease progression, which, if not treated, may lead to ESRD. While early intervention and management of body weight, hyperglycemia and hypertension are imperative, novel therapeutic approaches are also necessary to reduce the high morbidity and mortality associated with both obesity- and diabetes-related renal disease.

\section{Acknowledgments}

The authors acknowledge the financial support of NIH/NIDDK (RO1DK075832 to C. Maric-Bilkan).

\section{References}

1. Yanovski SZ, Yanovski JA. Obesity prevalence in the United States--up, down, or sideways? N Engl J Med. 2011 Mar 17; 364(11):987-989. [PubMed: 21410367]

2. Flegal KM, Carroll MD, Ogden CL, Curtin LR. Prevalence and trends in obesity among US adults, 1999-2008. JAMA. 2010 Jan 20; 303(3):235-241. [PubMed: 20071471]

3. Organization WH. Obesity and overweight fact sheet. 2012. http://www.who.int/mediacentre/ factsheets/fs311/en/index.html. 
4. Kopelman P. Health risks associated with overweight and obesity. Obes Rev. 2007 Mar; 8(Suppl 1): 13-17. [PubMed: 17316295]

5. Eknoyan G. Obesity, diabetes, and chronic kidney disease. Curr Diab Rep. 2007 Dec; 7(6):449-453. [PubMed: 18255009]

6. Hall JE, Crook ED, Jones DW, Wofford MR, Dubbert PM. Mechanisms of obesity-associated cardiovascular and renal disease. Am J Med Sci. 2002 Sep; 324(3):127-137. [PubMed: 12240710]

7. Ogden CL, Carroll MD, Curtin LR, McDowell MA, Tabak CJ, Flegal KM. Prevalence of overweight and obesity in the United States, 1999-2004. JAMA. 2006 Apr 5; 295(13):1549-1555. [PubMed: 16595758]

8. Neeland IJ, Turer AT, Ayers CR, et al. Dysfunctional adiposity and the risk of prediabetes and type 2 diabetes in obese adults. JAMA. 2012 Sep 19; 308(11):1150-1159. [PubMed: 22990274]

9. Foster MC, Hwang SJ, Larson MG, et al. Overweight, obesity, and the development of stage 3 CKD: the Framingham Heart Study. Am J Kidney Dis. 2008 Jul; 52(1):39-48. [PubMed: 18440684]

10. Hsu CY, McCulloch CE, Iribarren C, Darbinian J, Go AS. Body mass index and risk for end-stage renal disease. Ann Intern Med. 2006 Jan 3; 144(1):21-28. [PubMed: 16389251]

11. Ejerblad E, Fored CM, Lindblad P, Fryzek J, McLaughlin JK, Nyren O. Obesity and risk for chronic renal failure. J Am Soc Nephrol. 2006 Jun; 17(6):1695-1702. [PubMed: 16641153]

12. Praga M, Morales E. Obesity, proteinuria and progression of renal failure. Curr Opin Nephrol Hypertens. 2006 Sep; 15(5):481-486. [PubMed: 16914959]

13. Wang Y, Chen X, Song Y, Caballero B, Cheskin LJ. Association between obesity and kidney disease: a systematic review and meta-analysis. Kidney Int. 2008 Jan; 73(1):19-33. [PubMed: 17928825]

14. Ogden CL, Yanovski SZ, Carroll MD, Flegal KM. The epidemiology of obesity. Gastroenterology. 2007 May; 132(6):2087-2102. [PubMed: 17498505]

15. Coresh J, Selvin E, Stevens LA, et al. Prevalence of chronic kidney disease in the United States. JAMA. 2007 Nov 7; 298(17):2038-2047. [PubMed: 17986697]

16. Kramer H, Luke A, Bidani A, Cao G, Cooper R, McGee D. Obesity and prevalent and incident CKD: the Hypertension Detection and Follow-Up Program. Am J Kidney Dis. 2005 Oct; 46(4): 587-594. [PubMed: 16183412]

17. de Zeeuw D, Ramjit D, Zhang Z, et al. Renal risk and renoprotection among ethnic groups with type 2 diabetic nephropathy: a post hoc analysis of RENAAL. Kidney Int. 2006 May; 69(9):16751682. [PubMed: 16572114]

18. Remuzzi G, Macia M, Ruggenenti P. Prevention and treatment of diabetic renal disease in type 2 diabetes: the BENEDICT study. J Am Soc Nephrol. 2006 Apr; 17(4 Suppl 2):S90-S97. [PubMed: 16565256]

19. Health UNIo. Atlas of End-stage renal disease in the United States. Annual report. 2009.

20. Thomson SC, Vallon V, Blantz RC. Kidney function in early diabetes: the tubular hypothesis of glomerular filtration. Am J Physiol Renal Physiol. 2004 Jan; 286(1):F8-F15. [PubMed: 14656757]

21. Hostetter TH. Hyperfiltration and glomerulosclerosis. Semin Nephrol. 2003 Mar; 23(2):194-199. [PubMed: 12704579]

22. Caramori ML, Mauer M. Diabetes and nephropathy. Curr Opin Nephrol Hypertens. 2003 May; 12(3):273-282. [PubMed: 12698065]

23. Leon CA, Raij L. Interaction of haemodynamic and metabolic pathways in the genesis of diabetic nephropathy. J Hypertens. 2005 Nov; 23(11):1931-1937. [PubMed: 16208129]

24. Ogden CL, Carroll MD, Kit BK, Flegal KM. Prevalence of obesity and trends in body mass index among US children and adolescents, 1999-2010. JAMA. 2012 Feb 1; 307(5):483-490. [PubMed: 22253364]

25. Flegal KM, Carroll MD, Kit BK, Ogden CL. Prevalence of obesity and trends in the distribution of body mass index among US adults, 1999-2010. JAMA. 2012 Feb 1; 307(5):491-497. [PubMed: 22253363]

26. Danaei G, Finucane MM, Lin JK, et al. National, regional, and global trends in systolic blood pressure since 1980: systematic analysis of health examination surveys and epidemiological 
studies with 786 country-years and 5.4 million participants. Lancet. 2011 Feb 12; 377(9765):568577. [PubMed: 21295844]

27. National Institutes of Diabetes DaKD, the National Institutes of Health. U. S. Renal Data System: USRDS 2006 annual data report. 2006 NIDDK The National Institutes of Health. 2006.

28. Kurella M, Lo JC, Chertow GM. Metabolic syndrome and the risk for chronic kidney disease among nondiabetic adults. J Am Soc Nephrol. 2005 Jul; 16(7):2134-2140. [PubMed: 15901764]

29. Chen J, Muntner P, Hamm LL, et al. The metabolic syndrome and chronic kidney disease in U.S. adults. Ann Intern Med. 2004 Feb 3; 140(3):167-174. [PubMed: 14757614]

30. Stengel B, Tarver-Carr ME, Powe NR, Eberhardt MS, Brancati FL. Lifestyle factors, obesity and the risk of chronic kidney disease. Epidemiology. 2003 Jul; 14(4):479-487. [PubMed: 12843775]

31. Gelber RP, Kurth T, Kausz AT, et al. Association between body mass index and CKD in apparently healthy men. Am J Kidney Dis. 2005 Nov; 46(5):871-880. [PubMed: 16253727]

32. Munkhaugen J, Lydersen S, Wideroe TE, Hallan S. Prehypertension, obesity, and risk of kidney disease: 20-year follow-up of the HUNT I study in Norway. Am J Kidney Dis. 2009 Oct; 54(4): 638-646. [PubMed: 19515474]

33. Iseki K, Ikemiya $\mathrm{Y}$, Kinjo $\mathrm{K}$, Inoue $\mathrm{T}$, Iseki $\mathrm{C}$, Takishita $\mathrm{S}$. Body mass index and the risk of development of end-stage renal disease in a screened cohort. Kidney Int. 2004 May; 65(5):18701876. [PubMed: 15086929]

34. Kramer HJ, Saranathan A, Luke A, et al. Increasing body mass index and obesity in the incident ESRD population. J Am Soc Nephrol. 2006 May; 17(5):1453-1459. [PubMed: 16597682]

35. Kalantar-Zadeh K, Kopple JD. Obesity paradox in patients on maintenance dialysis. Contrib Nephrol. 2006; 151:57-69. [PubMed: 16929133]

36. Kalantar-Zadeh K, Streja E, Kovesdy CP, et al. The obesity paradox and mortality associated with surrogates of body size and muscle mass in patients receiving hemodialysis. Mayo Clin Proc. 2010 Nov; 85(11):991-1001. [PubMed: 21037042]

37. Elsayed EF, Sarnak MJ, Tighiouart H, et al. Waist-to-hip ratio, body mass index, and subsequent kidney disease and death. Am J Kidney Dis. 2008 Jul; 52(1):29-38. [PubMed: 18511168]

38. Elsayed EF, Tighiouart H, Weiner DE, et al. Waist-to-hip ratio and body mass index as risk factors for cardiovascular events in CKD. Am J Kidney Dis. 2008 Jul; 52(1):49-57. [PubMed: 18514990]

39. Henegar JR, Bigler SA, Henegar LK, Tyagi SC, Hall JE. Functional and structural changes in the kidney in the early stages of obesity. J Am Soc Nephrol. 2001 Jun; 12(6):1211-1217. [PubMed: 11373344]

40. Maddox DA, Alavi FK, Santella RN, Zawada ET Jr. Prevention of obesity-linked renal disease: age-dependent effects of dietary food restriction. Kidney Int. 2002 Jul; 62(1):208-219. [PubMed: 12081580]

41. Chagnac A, Weinstein T, Herman M, Hirsh J, Gafter U, Ori Y. The effects of weight loss on renal function in patients with severe obesity. J Am Soc Nephrol. 2003 Jun; 14(6):1480-1486. [PubMed: 12761248]

42. Hall JE. The kidney, hypertension, and obesity. Hypertension. 2003 Mar; 41(3 Pt 2):625-633. [PubMed: 12623970]

43. Griffin KA, Kramer H, Bidani AK. Adverse renal consequences of obesity. Am J Physiol Renal Physiol. 2008 Apr; 294(4):F685-F696. [PubMed: 18234955]

44. Hall JE, Kuo JJ, da Silva AA, de Paula RB, Liu J, Tallam L. Obesity-associated hypertension and kidney disease. Curr Opin Nephrol Hypertens. 2003 Mar; 12(2):195-200. [PubMed: 12589181]

45. Esler M, Rumantir M, Wiesner G, Kaye D, Hastings J, Lambert G. Sympathetic nervous system and insulin resistance: from obesity to diabetes. Am J Hypertens. 2001 Nov; 14(11 Pt 2):304S309S. [PubMed: 11721888]

46. Blanco S, Bonet J, Lopez D, Casas I, Romero R. ACE inhibitors improve nephrin expression in Zucker rats with glomerulosclerosis. Kidney Int Suppl. 2005 Jan.(93):S10-S14. [PubMed: 15613060]

47. Chagnac A, Herman M, Zingerman B, et al. Obesity-induced glomerular hyperfiltration: its involvement in the pathogenesis of tubular sodium reabsorption. Nephrol Dial Transplant. 2008 Dec; 23(12):3946-3952. [PubMed: 18622024] 
48. Yip JW, Jones SL, Wiseman MJ, Hill C, Viberti G. Glomerular hyperfiltration in the prediction of nephropathy in IDDM: a 10-year follow-up study. Diabetes. 1996 Dec; 45(12):1729-1733. [PubMed: 8922358]

49. Vallon V, Schroth J, Satriano J, Blantz RC, Thomson SC, Rieg T. Adenosine A(1) receptors determine glomerular hyperfiltration and the salt paradox in early streptozotocin diabetes mellitus. Nephron Physiol. 2009; 111(3):30-38.

50. Woods LL, Mizelle HL, Hall JE. Control of renal hemodynamics in hyperglycemia: possible role of tubuloglomerular feedback. Am J Physiol. 1987 Jan; 252(1 Pt 2):F65-F73. [PubMed: 3812702]

51. Persson P, Hansell P, Palm F. Tubular reabsorption and diabetes-induced glomerular hyperfiltration. Acta Physiol (Oxf). 2010 Sep; 200(1):3-10. [PubMed: 20518753]

52. Cherney DZ, Scholey JW, Miller JA. Insights into the regulation of renal hemodynamic function in diabetic mellitus. Curr Diabetes Rev. 2008 Nov; 4(4):280-290. [PubMed: 18991597]

53. Carmines PK. The renal vascular response to diabetes. Curr Opin Nephrol Hypertens. 2010 Jan; 19(1):85-90. [PubMed: 19770755]

54. do Carmo JM, Tallam LS, Roberts JV, et al. Impact of obesity on renal structure and function in the presence and absence of hypertension: evidence from melanocortin-4 receptor-deficient mice. Am J Physiol Regul Integr Comp Physiol. 2009 Sep; 297(3):R803-R812. [PubMed: 19605765]

55. Fried LF, Orchard TJ, Kasiske BL. Effect of lipid reduction on the progression of renal disease: a meta-analysis. Kidney Int. 2001 Jan; 59(1):260-269. [PubMed: 11135079]

56. Must A, Spadano J, Coakley EH, Field AE, Colditz G, Dietz WH. The disease burden associated with overweight and obesity. JAMA. 1999 Oct 27; 282(16):1523-1529. [PubMed: 10546691]

57. Wilson PW, D'Agostino RB, Sullivan L, Parise H, Kannel WB. Overweight and obesity as determinants of cardiovascular risk: the Framingham experience. Arch Intern Med. 2002 Sep 9; 162(16):1867-1872. [PubMed: 12196085]

58. Doll S, Paccaud F, Bovet P, Burnier M, Wietlisbach V. Body mass index, abdominal adiposity and blood pressure: consistency of their association across developing and developed countries. Int $\mathrm{J}$ Obes Relat Metab Disord. 2002 Jan; 26(1):48-57. [PubMed: 11791146]

59. Hall JE, Jones DW, Kuo JJ, da Silva A, Tallam LS, Liu J. Impact of the obesity epidemic on hypertension and renal disease. Curr Hypertens Rep. 2003 Oct; 5(5):386-392. [PubMed: 12948431]

60. Neter JE, Stam BE, Kok FJ, Grobbee DE, Geleijnse JM. Influence of weight reduction on blood pressure: a meta-analysis of randomized controlled trials. Hypertension. 2003 Nov; 42(5):878884. [PubMed: 12975389]

61. Garrison RJ, Kannel WB, Stokes J 3rd, Castelli WP. Incidence and precursors of hypertension in young adults: the Framingham Offspring Study. Prev Med. 1987 Mar; 16(2):235-251. [PubMed: 3588564]

62. Kannel WB, Zhang T, Garrison RJ. Is obesity-related hypertension less of a cardiovascular risk? The Framingham Study. Am Heart J. 1990 Nov; 120(5):1195-1201. [PubMed: 2239671]

63. Mokdad AH, Ford ES, Bowman BA, et al. Prevalence of obesity, diabetes, and obesity-related health risk factors, 2001. JAMA. 2003 Jan 1; 289(1):76-79. [PubMed: 12503980]

64. Kotchen TA. Obesity-related hypertension: epidemiology, pathophysiology, and clinical management. Am J Hypertens. 2010 Nov; 23(11):1170-1178. [PubMed: 20706196]

65. Hall JE, Henegar JR, Dwyer TM, et al. Is obesity a major cause of chronic kidney disease? Adv Ren Replace Ther. 2004 Jan; 11(1):41-54. [PubMed: 14730537]

66. Van Buren PN, Toto R. Hypertension in diabetic nephropathy: epidemiology, mechanisms, and management. Adv Chronic Kidney Dis. 2011 Jan; 18(1):28-41. [PubMed: 21224028]

67. Mancia G. Effects of intensive blood pressure control in the management of patients with type 2 diabetes mellitus in the Action to Control Cardiovascular Risk in Diabetes (ACCORD) trial. Circulation. 2010 Aug 24; 122(8):847-849. [PubMed: 20733113]

68. Heerspink HJ, de Zeeuw D. The kidney in type 2 diabetes therapy. Rev Diabet Stud. 2011 Fall; 8(3):392-402. [PubMed: 22262076]

69. Rayner HC, Hollingworth L, Higgins R, Dodds S. Systematic kidney disease management in a population with diabetes mellitus: turning the tide of kidney failure. BMJ Qual Saf. 2011 Oct; 20(10):903-910. 
70. Williams ME. The goal of blood pressure control for prevention of early diabetic microvascular complications. Curr Diab Rep. 2011 Aug; 11(4):323-329. [PubMed: 21526351]

71. Grossman E, Messerli FH. Management of blood pressure in patients with diabetes. Am J Hypertens. 2011 Aug; 24(8):863-875. [PubMed: 21525967]

72. Jauregui A, Mintz DH, Mundel P, Fornoni A. Role of altered insulin signaling pathways in the pathogenesis of podocyte malfunction and microalbuminuria. Curr Opin Nephrol Hypertens. 2009 Nov; 18(6):539-545. [PubMed: 19724224]

73. de Boer IH, Sibley SD, Kestenbaum B, et al. Central obesity, incident microalbuminuria, and change in creatinine clearance in the epidemiology of diabetes interventions and complications study. J Am Soc Nephrol. 2007 Jan; 18(1):235-243. [PubMed: 17151331]

74. Eijkelkamp WB, Zhang Z, Remuzzi G, et al. Albuminuria is a target for renoprotective therapy independent from blood pressure in patients with type 2 diabetic nephropathy: post hoc analysis from the Reduction of Endpoints in NIDDM with the Angiotensin II Antagonist Losartan (RENAAL) trial. J Am Soc Nephrol. 2007 May; 18(5):1540-1546. [PubMed: 17409317]

75. Klausen KP, Parving HH, Scharling H, Jensen JS. Microalbuminuria and obesity: impact on cardiovascular disease and mortality. Clin Endocrinol (Oxf). 2009 Jul; 71(1):40-45. [PubMed: 18803675]

76. Savage S, Nagel NJ, Estacio RO, Lukken N, Schrier RW. Clinical factors associated with urinary albumin excretion in type II diabetes. Am J Kidney Dis. 1995 Jun; 25(6):836-844. [PubMed: 7771479]

77. de Jong PE, Verhave JC, Pinto-Sietsma SJ, Hillege HL. Obesity and target organ damage: the kidney. Int J Obes Relat Metab Disord. 2002 Dec; 26(Suppl 4):S21-S24. [PubMed: 12457295]

78. Kohler KA, McClellan WM, Ziemer DC, Kleinbaum DG, Boring JR. Risk factors for microalbuminuria in black americans with newly diagnosed type 2 diabetes. Am J Kidney Dis. 2000 Nov; 36(5):903-913. [PubMed: 11054346]

79. Pinto-Sietsma SJ, Navis G, Janssen WM, de Zeeuw D, Gans RO, de Jong PE. A central body fat distribution is related to renal function impairment, even in lean subjects. Am J Kidney Dis. 2003 Apr; 41(4):733-741. [PubMed: 12666059]

80. Morales E, Valero MA, Leon M, Hernandez E, Praga M. Beneficial effects of weight loss in overweight patients with chronic proteinuric nephropathies. Am J Kidney Dis. 2003 Feb; 41(2): 319-327. [PubMed: 12552492]

81. Praga M, Morales E. Obesity-related renal damage: changing diet to avoid progression. Kidney Int. 2010 Oct; 78(7):633-635. [PubMed: 20842147]

82. Mohan S, Tan J, Gorantla S, Ahmed L, Park CM. Early improvement in albuminuria in nondiabetic patients after Roux-en-Y bariatric surgery. Obes Surg. 2012 Mar; 22(3):375-380. [PubMed: 21590347]

83. Sharma K, Ramachandrarao S, Qiu G, et al. Adiponectin regulates albuminuria and podocyte function in mice. J Clin Invest. 2008 May; 118(5):1645-1656. [PubMed: 18431508]

84. Comper WD, Russo LM. The glomerular filter: an imperfect barrier is required for perfect renal function. Curr Opin Nephrol Hypertens. 2009 Jul; 18(4):336-342. [PubMed: 19474730]

85. Kasiske BL, Cleary MP, O'Donnell MP, Keane WF. Effects of genetic obesity on renal structure and function in the Zucker rat. J Lab Clin Med. 1985 Nov; 106(5):598-604. [PubMed: 4056570]

86. Tran HA. Obesity-related glomerulopathy. J Clin Endocrinol Metab. 2004 Dec.89(12):6358. [PubMed: 15579804]

87. Ritz E, Koleganova N, Piecha G. Is there an obesity-metabolic syndrome related glomerulopathy? Curr Opin Nephrol Hypertens. 2011 Jan; 20(1):44-49. [PubMed: 21088574]

88. Kasiske BL, Napier J. Glomerular sclerosis in patients with massive obesity. Am J Nephrol. 1985; 5(1):45-50. [PubMed: 3970078]

89. Coimbra TM, Janssen U, Grone HJ, et al. Early events leading to renal injury in obese Zucker (fatty) rats with type II diabetes. Kidney Int. 2000 Jan; 57(1):167-182. [PubMed: 10620198]

90. O'Donnell MP, Kasiske BL, Cleary MP, Keane WF. Effects of genetic obesity on renal structure and function in the Zucker rat. II. Micropuncture studies. J Lab Clin Med. 1985 Nov; 106(5):605610. [PubMed: 4056571] 
91. Kambham N, Markowitz GS, Valeri AM, Lin J, D'Agati VD. Obesity-related glomerulopathy: an emerging epidemic. Kidney Int. 2001 Apr; 59(4):1498-1509. [PubMed: 11260414]

92. Praga M, Hernandez E, Morales E, et al. Clinical features and long-term outcome of obesityassociated focal segmental glomerulosclerosis. Nephrol Dial Transplant. 2001 Sep; 16(9):1790_ 1798. [PubMed: 11522860]

93. Praga M. Synergy of low nephron number and obesity: a new focus on hyperfiltration nephropathy. Nephrol Dial Transplant. 2005 Dec; 20(12):2594-2597. [PubMed: 16223782]

94. King GL. The role of inflammatory cytokines in diabetes and its complications. J Periodontol. 2008 Aug; 79(8 Suppl):1527-1534. [PubMed: 18673007]

95. Tang J, Yan H, Zhuang S. Inflammation and oxidative stress in obesity-related glomerulopathy. Int J Nephrol. 2012; 2012608397.

96. Guebre-Egziabher F, Bernhard J, Funahashi T, Hadj-Aissa A, Fouque D. Adiponectin in chronic kidney disease is related more to metabolic disturbances than to decline in renal function. Nephrol Dial Transplant. 2005 Jan; 20(1):129-134. [PubMed: 15585515]

97. Saraheimo M, Forsblom C, Thorn L, et al. Serum adiponectin and progression of diabetic nephropathy in patients with type 1 diabetes. Diabetes Care. 2008 Jun; 31(6):1165-1169. [PubMed: 18346990]

98. Ma K, Cabrero A, Saha PK, et al. Increased beta -oxidation but no insulin resistance or glucose intolerance in mice lacking adiponectin. J Biol Chem. 2002 Sep 20; 277(38):34658-34661. [PubMed: 12151381]

99. Kastarinen H, Kesaniemi YA, Ukkola O. Leptin and lipid metabolism in chronic kidney failure. Scand J Clin Lab Invest. 2009; 69(3):401-408. [PubMed: 19148833]

100. Sharma K, Considine RV, Michael B, et al. Plasma leptin is partly cleared by the kidney and is elevated in hemodialysis patients. Kidney Int. 1997 Jun; 51(6):1980-1985. [PubMed: 9186891]

101. Mathew AV, Okada S, Sharma K. Obesity related kidney disease. Curr Diabetes Rev. 2011 Jan; 7(1):41-49. [PubMed: 21067508]

102. Wolf G, Ziyadeh FN. Leptin and renal fibrosis. Contrib Nephrol. 2006; 151:175-183. [PubMed: 16929141]

103. Park HS, Park JY, Yu R. Relationship of obesity and visceral adiposity with serum concentrations of CRP, TNF-alpha and IL-6. Diabetes Res Clin Pract. 2005 Jul; 69(1):29-35. [PubMed: 15955385]

104. Gupta J, Mitra N, Kanetsky PA, et al. Association between Albuminuria, Kidney Function, and Inflammatory Biomarker Profile. Clin J Am Soc Nephrol. 2012 Sep 27.

105. Ruiz-Ortega M, Ruperez M, Lorenzo O, et al. Angiotensin II regulates the synthesis of proinflammatory cytokines and chemokines in the kidney. Kidney Int Suppl. 2002 Dec.(82):S12S22. [PubMed: 12410849]

106. Ikezumi Y, Suzuki T, Karasawa T, Kawachi H, Nikolic-Paterson DJ, Uchiyama M. Activated macrophages down-regulate podocyte nephrin and podocin expression via stress-activated protein kinases. Biochem Biophys Res Commun. 2008 Nov 28; 376(4):706-711. [PubMed: 18809387]

107. Patel NS, Chatterjee PK, Di Paola R, et al. Endogenous interleukin-6 enhances the renal injury, dysfunction, and inflammation caused by ischemia/reperfusion. J Pharmacol Exp Ther. 2005 Mar; 312(3):1170-1178. [PubMed: 15572648]

108. Tomiyama-Hanayama M, Rakugi H, Kohara M, et al. Effect of interleukin-6 receptor blockage on renal injury in apolipoprotein E-deficient mice. Am J Physiol Renal Physiol. 2009 Sep; 297(3):F679-F684. [PubMed: 19570877]

109. Ahmed SB, Fisher ND, Stevanovic R, Hollenberg NK. Body mass index and angiotensindependent control of the renal circulation in healthy humans. Hypertension. 2005 Dec; 46(6): 1316-1320. [PubMed: 16286575]

110. Kennefick TM, Anderson S. Role of angiotensin II in diabetic nephropathy. Semin Nephrol. 1997 Sep; 17(5):441-447. [PubMed: 9316212]

111. Zhuo JL, Li XC. Novel roles of intracrine angiotensin II and signalling mechanisms in kidney cells. J Renin Angiotensin Aldosterone Syst. 2007 Mar; 8(1):23-33. [PubMed: 17487823] 
112. Griffin KA, Bidani AK. Progression of renal disease: renoprotective specificity of reninangiotensin system blockade. Clin J Am Soc Nephrol. 2006 Sep; 1(5):1054-1065. [PubMed: 17699327]

113. Crowley SD, Gurley SB, Coffman TM. AT(1) receptors and control of blood pressure: the kidney and more. Trends Cardiovasc Med. 2007 Jan; 17(1):30-34. [PubMed: 17210476]

114. Ziyadeh FN. Mediators of diabetic renal disease: the case for tgf-Beta as the major mediator. J Am Soc Nephrol. 2004 Jan; 15(Suppl 1):S55-S57. [PubMed: 14684674]

115. Jiang G, Li Z, Liu F, et al. Prevention of obesity in mice by antisense oligonucleotide inhibitors of stearoyl-CoA desaturase-1. J Clin Invest. 2005 Apr; 115(4):1030-1038. [PubMed: 15761499] 


\section{Key Points}

- The prevalence of obesity has risen to epidemic proportions and continues to be a major health problem worldwide.

- The high prevalence of obesity is closely linked to the increased incidence of a number of chronic diseases, including type 2 diabetes, hypertension and cardiovascular disease.

- Obesity, as well as type 2 diabetes, hypertension and cardiovascular disease are all risk factors for chronic kidney disease (CKD) and end-stage renal disease (ESRD).

- The mechanisms by which obesity independently, or in concert with type 2 diabetes and hypertension contributes to the development and/or progression of ESRD are not completely understood. 


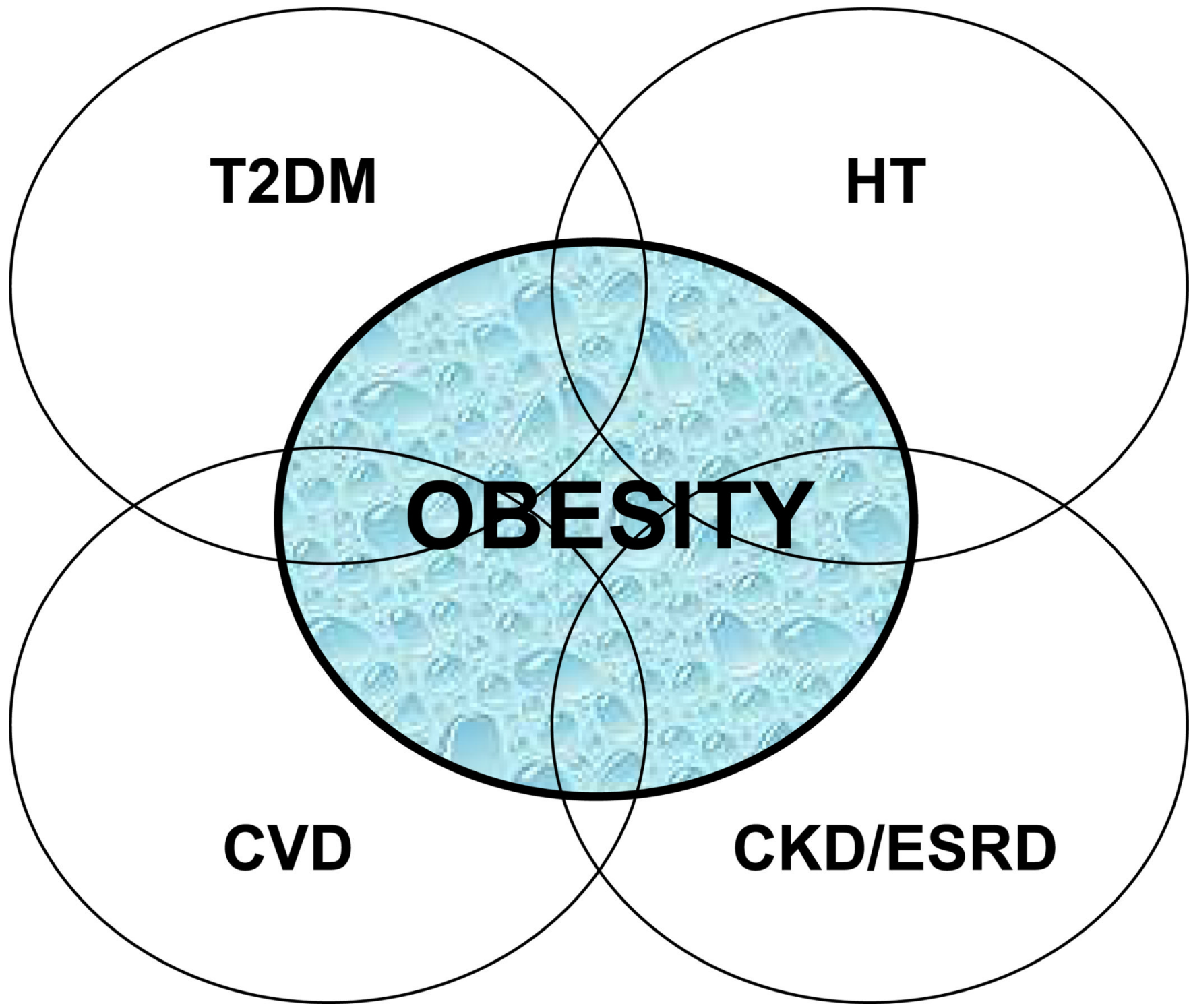

Figure 1. Clustering of risk factors for obesity-related renal disease

Obesity, type 2 diabetes (T2DM), hypertension (HT) and cardiovascular disease (CVD) are all risk factors for chronic kidney disease (CKD) and end-stage renal disease (ESRD). The presence of one or more of these risk factors multiplies the overall risk for disease development and progression. 


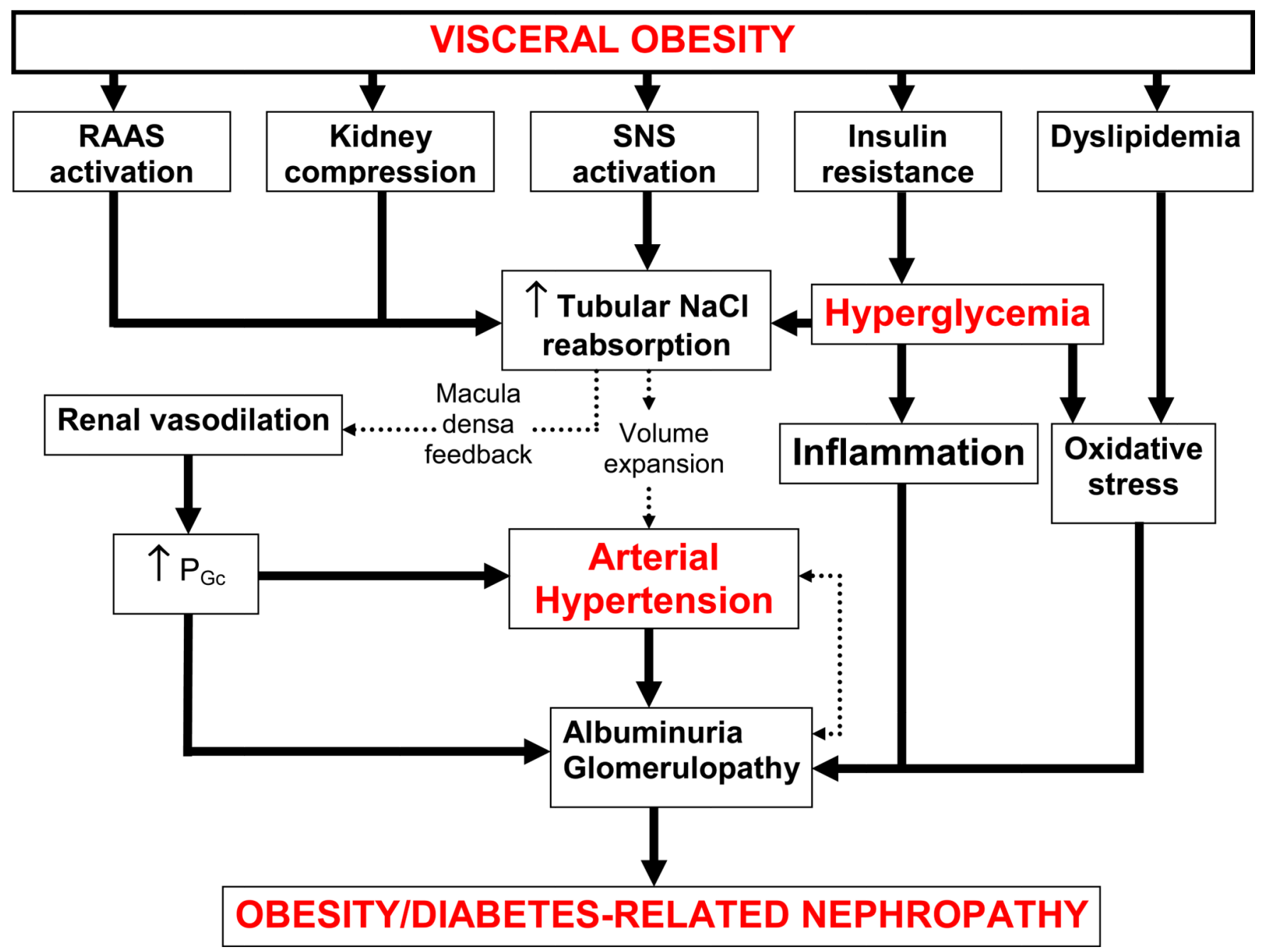

Figure 2. Interaction between metabolic and hemodynamic pathways in the pathophysiology of obesity-and diabetes-related renal disease

Abbreviations: SNS: sympathetic nervous system; RAAS, renin angiotensin aldosterone system; $\mathrm{P}_{\mathrm{Gc}}$, intraglomerular capillary pressure. 


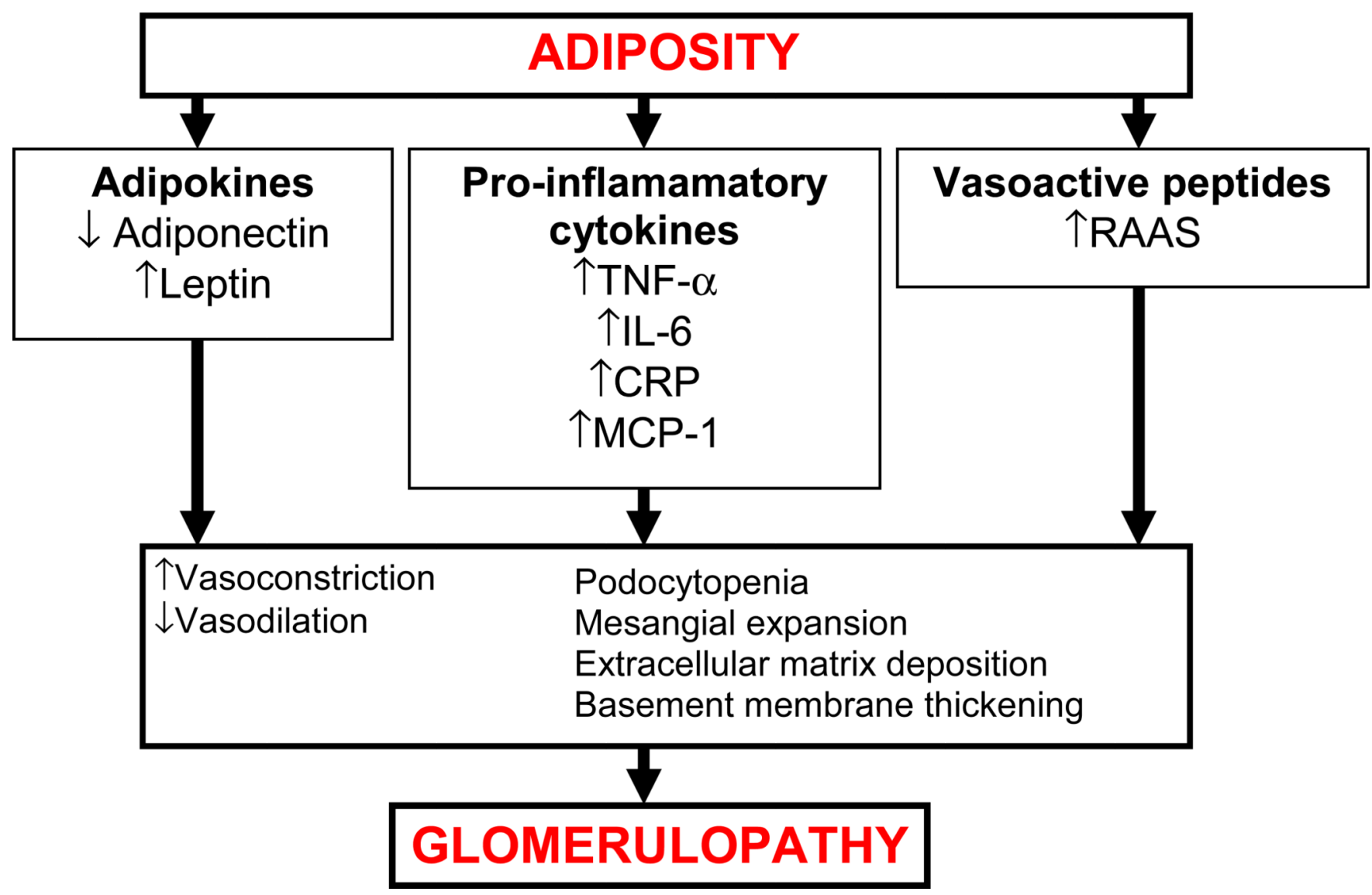

Figure 3. Mechanisms of obesity-related glomerulopathy

Abbreviations: TNF-a: tumor necrosis facor-a; IL-6, interleukin-6 system; CRP, C-reactive protein; CRP, MCP-1, monocyte chemoattractant protein-1; RAAS, renin angiotensin aldosterone system. 